NEWS

\title{
Iraqi death toll withstands scrutiny
}

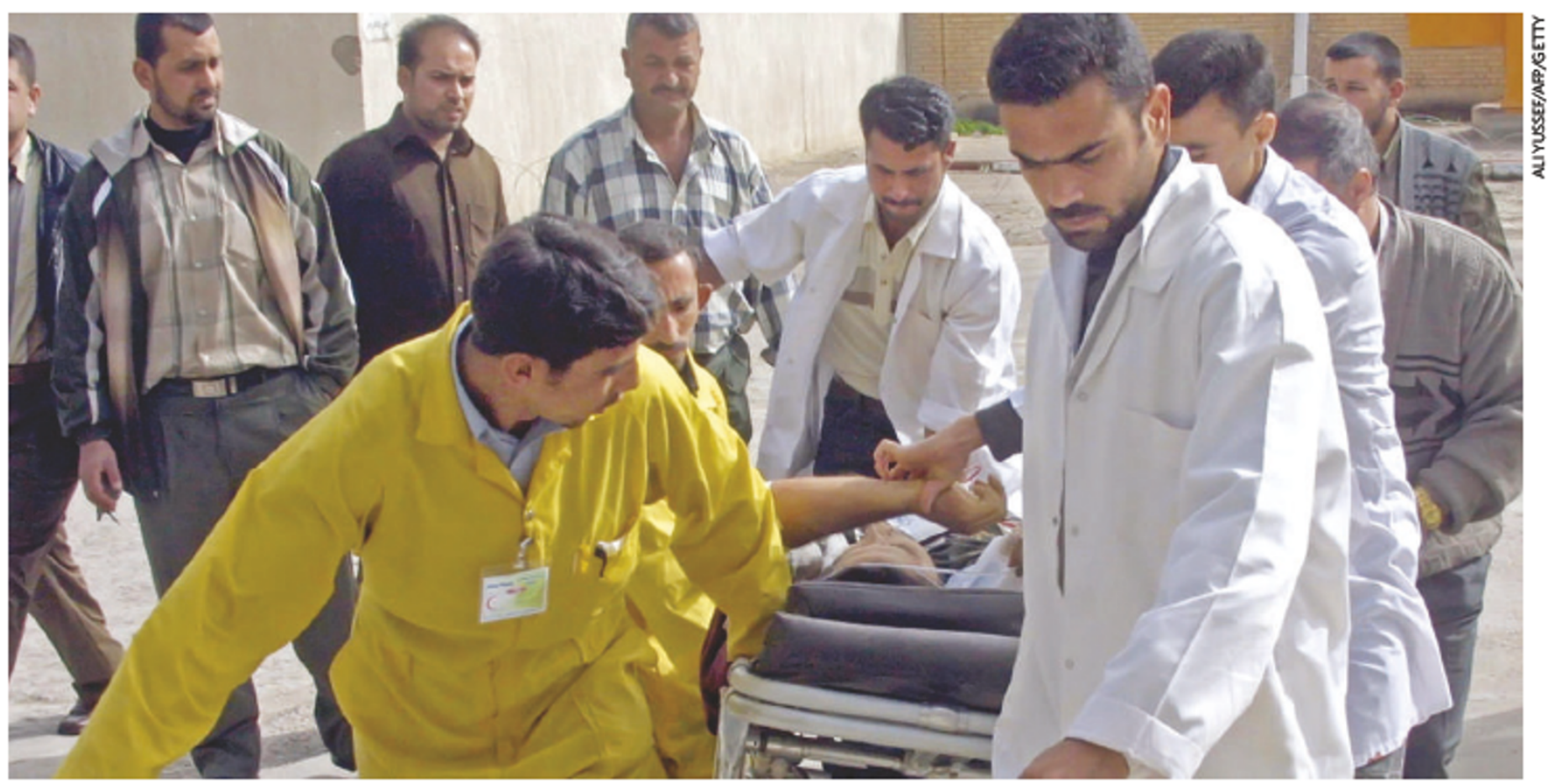

The uncertainty of figures relating to before the war, and the present security situation, hamper efforts to estimate the Iraqi deathrate.

It is one of the most politically charged questions that any researcher can tackle: how many people have died in Iraq since the USled invasion?

Four public-health experts provided an answer last week. Their result - a death rate that has risen from 5.5 per thousand per year to 13.3 - implies that since the invasion there have been 650,000 'excess' deaths, $2.5 \%$ of the population. Predictably, the finding has met with criticism from supporters of the war from the US president downwards.

If it holds, the study will be a key publication in the growing field of conflict epidemiology. Understanding who is dying, how and where in Iraq is vital for efforts to rebuild the country. So once the political criticisms are set aside, how does the study stack up scientifically?

\section{Counting the cost of war}

The Iraq study is justone of many that arehelping governments and aid agencies understand and respond to the impact of conflicts. Jana Asher of the Science and Human Rights Program of the American Association for the Advancement of Science in Washington DC has produced figures on which armed groups were responsible for deaths in the civil war in Sierra Leone in the 1990 s. She says that such studies have become increasingly importantover the past 15 years. The growth is due to improved methodology, and to the way that truth and reconciliation committees have come to be seen as an important way for nations to come to terms with a violent history.

Chile set up an early truth and reconciliation committee in 1990 , but the conceptcame to prominence in 1995, when a committee was setup in South Africa. Early committees generally collected qualitative evidence, such as eyewitness statements, says Asher. But the amount of data collected has increased vastly, and quantitative studies are now beingseen as part of a committee's work.

Recentstatisticalstudies include work on Darfur and East Timor. Bodies such as the International Criminal Court in the Hague, the Netherlands, can use the evidence from such surveys when prosecuting war criminals, such as cases relating to Sierra Leone. Most studies are uncontroversial, but the Iraq work is an exception because of the political debate over the US invasion.
Estimates of deaths in Iraq all suggest that the death rate has risen since the invasion. But they have been much lower than the latest figure. Iraq Body Count, a left-leaning website that compiles deaths from media reports, quotes a maximum of just under 49,000 . US government officials have given figures of $30,000-50,000$. And a household survey, conducted in May 2004 by the United Nations and published last year, concluded that the war had caused at least 18,000-29,000 deaths, mostly from violent causes. The only previous estimate of the same order of magnitude is a figure of around 100,000 excess deaths in the first 18 months of the conflict, published in 2004 by Gilbert Burnham and his colleagues at Johns Hopkins University in Baltimore (L. Roberts et al. Lancet 364, 1857-1864; 2004), the same researchers who are behind the new work.

The authors say their estimate is so much higher because their methodology is more comprehensive. They organized detailed interviews, carried out by Iraqi researchers from the Al Mustansiriya University in Baghdad, in more than 1,800 households in 16 of Iraq's 18 administrative regions. Using random sampling similar to that used in political opinion polls, they documented 82 deaths in the period before the invasion, and 547 during the conflict. More than $90 \%$ of these were confirmed by death 
certificates. They show a $95 \%$ probability that the death toll has been between 390,000 and 940,000 , most of which were due to violence such as gunshots (G. Burnham et al. Lancet doi:10.1016/S0140-6736(06)69491-9;2006).

Data from other conflicts show that such sampling is much more accurate than media reports, which usually account for no more than $20 \%$ of deaths. "Random counts force you to go to places that aren't convenient," says Jana Asher, a researcher with the Science and Human Rights Program of the American Association for the Advancement of Science in Washington DC. ${ }^{\alpha}$ The media don't wander off to distant locations. It's a very different type of data collection.

Death tolls from Iraqi health officials, the source of US government figures, are also suspect. The Johns Hopkins team says that the process for issuing death certificates still works well in Iraq, but the system for monitoring the number of certificates issued does not. Even before the war, note the researchers, the government's surveillance system captured only one-third of all deaths.

Yet despite the weakness of other measurements, the new figure has still surprised researchers. Perhaps the most significant con- cern is the baseline rate for pre-invasion death rates used in the new study. The latest survey, which included questions about the situation before the invasion, put this at 5.5 deaths per 1,000 people per year, in line with figures on Iraq from the US Census Bureau. Iran, which has a well-run health system, has a similar rate, but Iraq was at the time suffering from years of sanctions. Some sources, including the United Nations Population Division, list a pre-invasion figure of 9.7 .

The discrepancy does not invalidate the new result, and if the researchers underestimated the pre-war death rate, it's possible that they may have also underestimated the postwar rate. But some researchers say the paper should have addressed the issue. "There should have been more introspection," says Beth Osborne Daponte, a demographer at Carnegie Mellon University in Pittsburgh, Pennsylvania. "That increased my discomfort.

Other researchers share that discomfort. Debarati Guha-Sapir is director of the Centre for Research on the Epidemiology of Disasters in Brussels. She has some methodological concerns about the paper, including the use of local people - who might have opposed the occupa-
SMALLEST GENOME

CLOCKS IN AT 182 GENES How much can you remove froma bacterium before it stops working?

www.nature.com/news tion - as interviewers. She also points out that the result does not fit with any she has recorded in 15 years of studying conflict zones. Even in Darfur, where armed groups have wiped out whole villages, she says that researchers have not recorded the 500 predominately violent deaths per day that the Johns Hopkins team estimates are occurring in Iraq.

But overall Guha-Sapir says the paper contains the best data yet on the mortality rate in Iraq. And none of the experts contacted by Nature said that their doubts fatally undermined the study. Some, such as Daponte, would have liked the authors to have better assessed their method's shortcomings before releasing a result with such political impact. But most say the result is a welcome addition to conflict epidemiology, which is now seen as playing a central role in assessing the severity of wars, and in helping states recover from them (see 'Counting the cost of war').

Burnham says he would now like to study patterns of migration in Iraq and the state of the health system. He would also like to estimate deaths based on a sample 4-5 times bigger than that used so far. But survey teams are in danger on the streets of Iraqi towns, and Burnham doubts whether the need for more detailed data justifies the risk.

Jim Giles

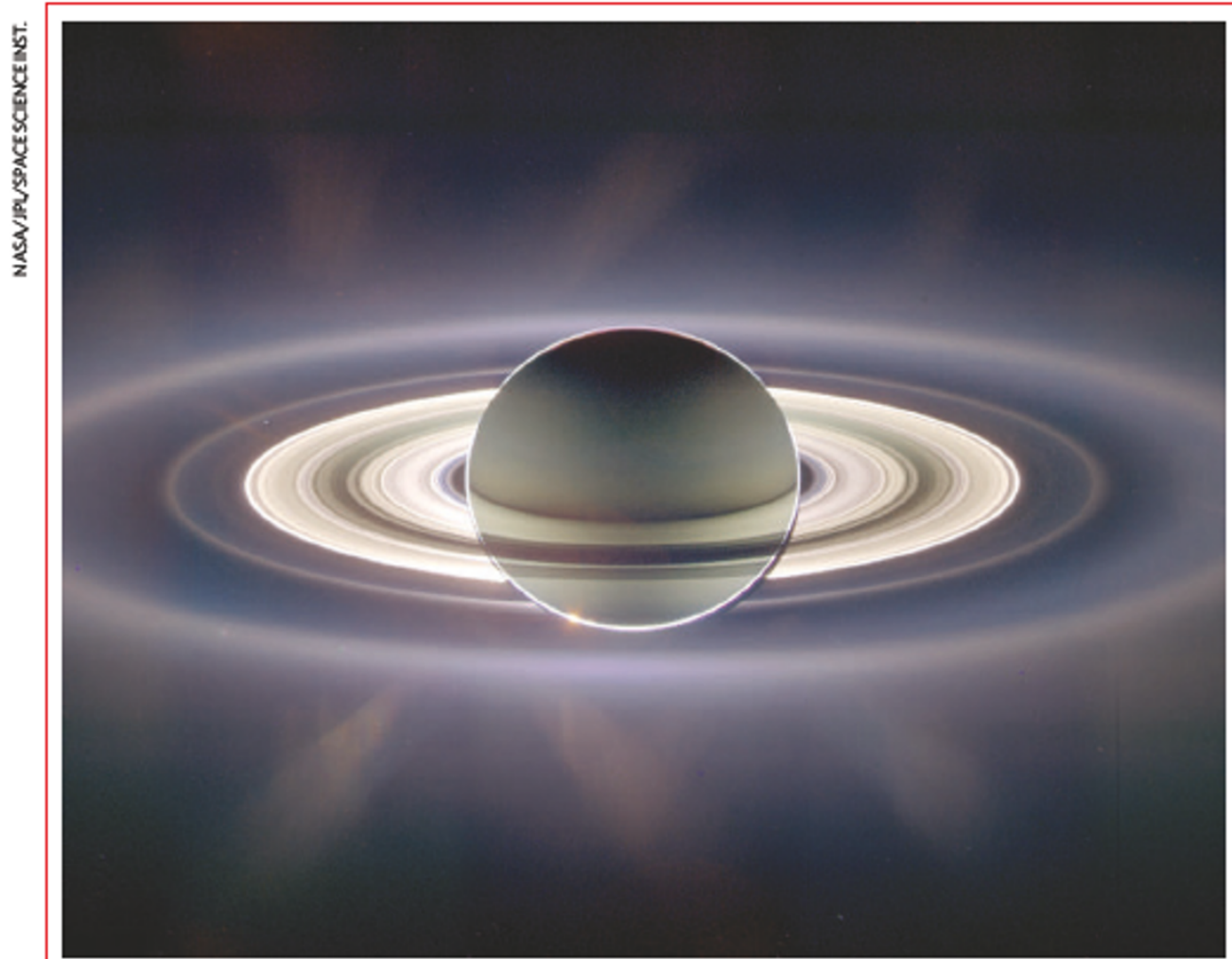

\section{SNAPSHOT Light show}

September broughta fantastic photo opportunity for Cassini, the spacecraftin orbit around Saturn. Its trajectory brought it into the ringed planet's shadow for about 12 hours on 15 September, giving it a striking view with the Sun lying directly behind

With the glare of the Sun blocked, Cassini's cameras could pick up light glinting from particles just $1-10$ micrometres across. The effect in this exaggerated-colour image issimilar, says Cassini imaging scientist Joe Burns of CornellUniversity in New York state, to the way that stray hairs are highlighted when someone is illuminated from behind.

The light show revealed several ringlets that haven't been seen before, the team reported at the American Astronomical Society's Division for Planetary Sciences Meeting in Pasadena, California, this week. One particularly bright ringlet, they say, may be the remains of a recently shattered moon.

Nicola Jones 